\title{
Article
}

\section{Complexity Science: Understanding Research Processes and Improving Research Practice}

Cox, Pat

Available at http://clok.uclan.ac.uk/6927/

Cox, Pat ORCID: 0000-0003-2565-4564 (2012) Complexity Science:

Understanding Research Processes and Improving Research Practice. Journal of Social Service Research, 38 (5). pp. 582-590. ISSN 0148-8376

It is advisable to refer to the publisher's version if you intend to cite from the work. http://dx.doi.org/10.1080/01488376.2012.721283

For more information about UCLan's research in this area go to http://www.uclan.ac.uk/researchgroups/ and search for < name of research Group>.

For information about Research generally at UCLan please go to http://www.uclan.ac.uk/research/

All outputs in CLoK are protected by Intellectual Property Rights law, including Copyright law. Copyright, IPR and Moral Rights for the works on this site are retained by the individual authors and/or other copyright owners. Terms and conditions for use of this material are defined in the policies page.

\section{CLoK}

Central Lancashire online Knowledge www.clok.uclan.ac.uk

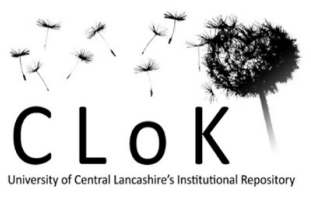


TITLE: Complexity science: Understanding research processes and improving research practice.

SHORTENED TITLE: Complexity science; research processes

\begin{abstract}
.
Reflecting on experiences of co-researching with young people aged thirteen to fifteen in evaluating a government-funded initiative within their own communities, the author explores both some of the consequences of this endeavour and learnings from reflections on research processes therein. Reflections upon lessons learned are analysed through applying some key concepts from complexity science to the research. It is argued that complexity science assists in reflection and in reaching more in-depth understandings of research processes. The author outlines how these concepts could be applied in research more generally and concludes that learnings from this experience are relevant to researchers everywhere.
\end{abstract}

KEYWORDS. Complexity science, research, research processes, learnings, evaluation.

\title{
INTRODUCTION
}

In this paper the author analyses and reflects upon the processes of a research project, one part of a four-part evaluation of a UK Children’s Fund Programme. While acknowledging debates about whether evaluation is or is not research (Robson, 2002), recognizable quantitative and qualitative research methods were deployed throughout this project and so in this paper, research and evaluation are elided (Cresswell, 2003). The paper opens with a summary of the Children's Fund initiative and project background. This is followed by an account of some key concepts in complexity science and a narrative which includes recruiting 
and co-researching with young people; issues in managing tasks; understandings and expectations among the research team and with the Programme Management Board. Complexity science concepts are applied to the processes of this project and discussed. In keeping with complexity science principles (Mainzer 1996), the focus of this paper is the learnings from the research processes, rather than research knowledge. The author acknowledges the dangers in uncritical transference of concepts between disciplines and engages critically with complexity science in order to engender deeper understandings of research practice and processes, applying it as a model which has explanatory worth and seeking resonances, rather than an exact mapping (Varela, 1989). This project took place several years ago; this account is the author's own (Moore, 1994) and analysis and reflections here are not necessarily shared either by former colleagues or by the young researchers.

The author and an academic colleague were recruited to this project by the principal investigator. The author was a less experienced researcher then, only beginning her explorations of complexity science and its relevance to research, practice and teaching. With greater - although still incomplete - understandings of the contribution of complexity science concepts to researching the social world (Cox 2008), the author's ongoing reflections on this project’s processes are enhanced by application of complexity science concepts.

\section{THE CHILDREN'S FUND}

The Children's Fund was one of a series of initiatives brought in by the UK Blair Labour government (Home Office, 1998), aiming to improve the life chances of children and young people living in areas high on indices of poverty and other forms of deprivation and encouraging social services, health and education to set up programmes addressing social exclusion and promoting the well-being of children and young people aged 5-13, and their families. It was a funding stream, not itself a provider of services. Children’s Fund 
Programmes were to be evaluated during their two-three year duration by researchers wholly independent of the programmes, with the government requiring children's views and participation to be central in the Fund's evaluation (Jack, 2005).

\section{PROJECT BACKGROUND}

The principal investigator, the author and academic colleague agreed to recruit local young people as co-researchers and that young people recruited would be those who would not usually be asked to participate in such a project. It was anticipated that this initiative would address the participation imperative, contributing to the development of local young people who were not themselves subjects of the evaluation. This Children's Fund programme was located in a district (hereafter Northside), characterized mainly by high levels of poverty and unemployment, having a world ranking based on measures of child poverty and multiple deprivation indices. The Children’s Fund Programme partnership had designed four different projects in four separate areas of Northside.

\section{COMPLEXITY SCIENCE: KEY CONCEPTS}

Complexity science thinking within the natural sciences beginning in the nineteenth century continues into the twentieth and twenty-first centuries, with scholars from politics, social policy and social work applying complexity science (sometimes complexity theory) within their disciplines (Cox, 2008). Awareness of complexity science’s worth for understanding issues in social work practice and education (Stevens and Cox, 2008; Wolf-Branigin, 2009) and social work research (Trevillion, 2000; Wolf-Branigin in press) is developing. Concepts from complexity science most relevant for understanding processes in Northside Children's Fund Programme evaluation are: deterministic chaos; complex adaptive systems; non-linear 
relationships; emergence; networks; the inter-connections between networks and agents and the demise of history as the 'master key’ (Cilliers, 1998).

The concept of 'deterministic chaos' was developed by nineteenth-century mathematician Poincaré (1914) and deployed to describe the impossibility of predicting the orbits of the planets for all time because the orbits change in unforeseen ways. Thus while planetary observers can anticipate some change or movement, they cannot forecast exactly what movement will occur, or when or how. Morowitz (2002) observes that Poincaré's concept is central to complexity.

For the author, the concept of deterministic chaos (which is not complete randomness or chaos) resonates with many research endeavours - and this one in particular - in that every researcher's past and current experiences of the progress of projects does not enable any researcher to anticipate or predict either processes or knowledge production with any certainty: attempts to forecast may be comforting, but they are unlikely to be accurate.

Complex adaptive systems are open systems which are organic and dynamic, existing on the border of order and chaos. Merry (1995) notes that complex systems cannot be understood by reducing them to their parts. They affect, and are affected by, their surroundings. They may respond to feedback but there is often no correspondence between input to the system and the output that follows. One small change in one component of a complex adaptive system may result in large-scale unpredictable changes, or it may result in no change at all. Holland (1986) asserts that complex adaptive systems describes not only biological systems but also social systems: therefore teams, committees and communities all can be described as selforganising systems on the edge of chaos. 'Complex systems are open systems: when observed, the observer becomes part of the system.' (Burton, 2002, 2). Researchers often are 'observing' (researching or evaluating) a service, a programme or organizational practices, 
and researcher (observer) impact is valuable data.

Non-linear relationships do not imply that an increase in one variable will result in a uniform increase in another variable (Gribbin, 2004). Increased researcher input - more interviews, perhaps - may not result in richer or clearer data; may result in unexpected data, or not much data at all. This has obvious implications for research and evaluation projects and outputs.

Emergence implies that the developed whole is different to the sum of its parts: either more than, or less than. Emergence in complexity science thinking demonstrates that large-scale consequences can arise from small triggers: Cohen and Stewart (1994) and argue that emergence is a rule, rather than an exception; see also Morowitz (2002). The generation of data from commissioned research or evaluation (Griffiths, 2002) through the interaction of researchers and research subjects (Kvale and Brinkmann, 2008) may not be what research commissioners or researchers had expected.

Networks and inter-connections between simple parts and the manner of inter-connections are also concepts with relevance for understanding research. For example, if and how connections between events are made - or not made - influences research findings. Researchers who disregard or remove 'disconfirming observations' (Stewart, 1998, 22) during data collection or analysis can determine different findings and outcomes. Complexity science provides a non-hierarchical view of researchers' relationships with research subjects as inter-relationships as one of a variety of networks. Thus exploration (and understanding) of researchers' impact on relationships within the networks is essential. Applying these concepts, data can be shared with groups who can use it (service users, carers, service providers and funders), and emergent issues explored openly (Blackman, 2001). 
Agents have the capacity to share information amongst themselves, with others in their environment and to adjust their behaviour as a result of the information that they process. Agents have varying amounts of information and no one agent understands the system in its entirety. Agents have agency (in the social theoretical sense). They are influenced by their history, but not determined by it. Agents interact with their environment; agents develop and adapt as the environment changes, sometimes for reasons that they do not recognise fully.

The demise of history as the 'master key' (Cilliers, 1998) is a complexity science concept which emphasizes the unpredictability of future outcomes and in which previous histories offer no reliable guide to present or to future relationships or actions.

\section{RECRUITMENT AND BUILDING A TEAM}

The author and her colleague obtained introductions to local schools and to students (aged thirteen to sixteen), who are not normally chosen for such projects. A positive response from one school led to group interviews with thirteen students who had returned application forms and consent letters from parents and carers, with students contributing thoughtfully to group discussions. From among these thirteen, a group of nine - three young women and six young men aged from thirteen to fifteen - attended and contributed to research training sessions. Payment, in appropriate vouchers, was made for attending training and all work thereafter.

However, assumptions that one team of local researchers could be recruited to undertake research across Northside were unfounded. They had a strong sense of territorialism and were unwilling to enter areas of Northside with which they were unfamiliar or about which they already knew; such as perceived differences between estates and particular parts of estates.

In the months following training, a smaller group of six researchers emerged from amongst this group of nine. Members of this team worked well together, undertaking individual 
interviews with Children's Fund management and staff teams and focus groups with younger children who had participated in one of the Children's Fund four projects. They also undertook a community survey. They assisted in the research design and commented on questions (in interviews, focus groups and the community survey) which worked well; questions respondents had difficulty in answering and suggested alternatives for questions which did not work. Their detailed knowledge of Northside - areas where local children and young people, including themselves, would or wouldn't go - contributed significantly to the planning of interviews, focus groups and the community survey (Durand Thomas et al, 2000). Their knowledge also influenced how some of the research activities were set up.

Involvement and engagement of the others amongst the nine was more sporadic for various reasons. Sometimes they had more interesting things to do; sometimes they had pre-existing arrangements with friends, family or visits with a separated parent. Each young person was offered an opportunity to participate in every task, to whichever degree they specified; given their daily experiences of adult insistence on compliance, the author and colleague invited and encouraged everyone, but did not insist on anyone’s participation. Ellis (2007) notes coresearchers' needs to enjoy 'privacy and restraint' with and from one another; although this work was not published at that time, this was the instinctive approach adopted.

\section{REFLECTIONS}

The proposal for the contract for this evaluation was prepared to a very tight deadline. After initial discussions about recruiting and training young researchers, completion of a viable bid within the timescales became the focus of preparation, with two results. Firstly: the practical tasks underpinning the involvement of young researchers in the evaluation were not planned for in detail and practical issues had to be addressed as they arose; secondly: for the author, reflection in the remainder of the design process (and later in the research process) was 
shared usually with her immediate colleague; reflective and reflexive sessions with the principal investigator occurred less often. Involvement of the young researchers was only one part of the four-part evaluation: ongoing simultaneously was evaluation of the three other Children's Fund Programme projects. It became difficult for the author and colleague to attend equally to all four projects and maintain evaluation of them all at comparable rates of progress, while providing additional support for the young researchers.

Because this Children's Fund Programme had four different projects in four separate areas and the young researchers were unwilling to enter certain Northside districts, many interviews and focus groups were arranged in central locations that were acceptable to the young researchers and to their parents and carers. The author and colleague acted as supporters and escorts, collecting the young researchers from school or home, bringing them to venues where they undertook interviews or focus groups and then accompanying (some) home again. All recruitment and training sessions, each interview, focus group and the community survey evenings necessitated the author and colleague buying, setting out and clearing away refreshments, or buying takeaways or meals. These 'invisible’ tasks and time had to be factored into each research contact.

The Children's Fund lead body had an office in Northside, but it was too small to use as a venue for meeting or having refreshments with the young researchers. Casual chat or discussing task or process were during travelling to and from, or while eating before or after research activities. Unsurprisingly, at the start the young researchers preferred to talk together, rather than with the adults. Gradually, ongoing project involvement and consistency and reliability from the author and colleague meant that the regular group became more trusting and discussions opened up. 
The agenda of contributing to the young people's development through the process of coresearching was met during this process. One example: responses to the community survey were greater than anticipated because two of the young researchers lived in the area and were well-known and popular there: their delight in the recognition of their positive contribution to the survey responses radiated across the group and was reinforced by them and by the author and colleague. Self-assessment measures undertaken by the young researchers at the start and end of their involvement confirmed increased self-esteem and self-confidence levels.

Promoting the development of the young researchers did not always mesh with the agenda of the Programme’s Management Board. Understandably the Management Board wanted a range of data demonstrating the success of their Programme, whereas the author and colleague saw their responsibilities not only as producing data, but also supporting young coresearchers in learning from their mistakes and successes, developing skills and confidence.

\section{UNFORESEEN AND UNFORESEEABLE CHANGES}

The author and colleague had realised that the time allowed for evaluating Northside's Children's Fund Programme was insufficient to undertake development and maintenance work with young co-researchers and that designated time for this should have been built into the bid. There was a hiatus between the community survey in mid-July and their next task in September, interviewing staff in local welfare agencies about involving young residents in decision-making. The hiatus was due to lack of information on the progress of the relevant project in its work with the agencies, resulting in being unable to offer the co-researchers firm plans for interviewing in September. The author maintained contact with the young researchers; however in September the lead body required that the focus of the evaluation 
shift to assessing the individual projects in relation to their objectives; involving the coresearchers was eclipsed by having to adjust plans.

Repercussions of this shift in focus included a decision made in November by the Programme Management Board, with agreement from the principal investigator, to appoint a research assistant to be based in Northside and supervised by the Programme Manager. The author and colleague continued the evaluation until the appointment was made.

\section{DISCUSSION: APPLYING COMPLEXITY SCIENCE CONCEPTS FOR ANALYSIS}

Fixed and short-term time scales, characteristic of evaluations such as this, are problematic for researchers in that time-led drivers don't allow for continually evolving processes and relationships; nor do they allow for extensions to follow previously unconsidered paths of inquiry which become visible after the start.

Deterministic chaos reminds researchers of the impossibility of predicting processes or knowledge production accurately. In this evaluation, the territorialism of the young coresearchers and lack of space in the local office could not have been predicted, necessitating changes in where research activities were located and arranged and an increase in underpinning tasks; all of which impacted on data production.

Complex adaptive systems cannot be understood by reducing them to their parts and the author and colleague understood parts of the system only. Burton's (2002) consideration of observers as part of the system is apposite here: the author and colleague could have reflected more upon their impact (or lack of it) on all other parts of the system: for example, with workers and the Management Board, not only (as they did) their impact upon relationships with young co-researchers. 
However assiduously the author, colleague and co-researchers gathered and analysed data, decisions were taken about the form of the evaluation after September which had nothing to do with their input. In terms of non-linear relationships, the author and colleague were increasing their own 'variable' (involving co-researchers in more data collection activities), while the lead body's response did not represent a 'uniform increase'.

A problem with bidding for contracts such as this evaluation, is that researchers have to specify methodology and methods and so some possibilities for emergence are closed off, although others may be discerned once work is underway. The co-working relationships which developed between the author and colleague and young people who had no particular reason to trust adults is one example of emergence. The original decision to recruit young researchers resulted in improved understandings of the various areas within Northside, avoiding mistakes which the adult evaluators' lack of local knowledge might have caused. Finally, the co-researchers’ input into survey design and their post-hoc feedback improved interview, focus group and survey schedules. These examples of emergence - co-working relationships; significant local knowledge influencing processes; research design and data collection - probably were not anticipated by those who commissioned the evaluation.

Networks and inter-connections between simple parts can influence outcomes significantly. The format for supplying data was set early in the life of this programme by the Management Board. The author and colleague worked with the young researchers, evaluated three other programme projects, analysed data and submitted reports to the principal investigator, who submitted them forwards to the Management Board. It seemed that the Management Board then relayed findings to workers and volunteers in the Children's Fund Programme at second or third hand, with no opportunity for adult and young researchers to discuss data collection processes or the implications of findings with programme workers. Connections between the 
research team and workers were irregular and due partly to how findings were relayed, there were occasional difficulties in relationships with some staff and the Programme Management Board. The author recognizes how applying complexity science concepts would have expedited clearer understandings of (here a disconnect) in networks and inter-connections, enabling challenges to unhelpful practices driven by the demands of various agency agendas.

As agents the author and her colleague had limited knowledge of the Programme Management Board’s plans and how local Northside politics and national policy influenced their thinking. The author and her colleague knew all four projects and how the data for each was building; the young researchers were aware of the other three projects but did not know much about their data. The Programme Management Board (also agents) appeared to know very little about logistics and processes in co-working with young researchers. The coresearchers knew how local residents were responding to interview, survey and focus group questions. All agents had varying amounts of information, but no one agent understood all parts of the system, or the level of everyone's involvement, in its entirety. Everyone acted with agency and all developed and adapted to the environment until, in the case of the author, her colleague and co-researchers, adaptation made no further difference.

The demise of history as the 'master key' is illustrated in four examples. Firstly: the history of hard work by the author, her colleague and co-researchers was no assurance of the security of their future involvement. Secondly: the nature of working relationships established between the author, her colleague and the young co-researchers; these relationships might have been stronger or weaker: the young peoples’ earlier experiences of relationships with adults were no guide in this matter. Thirdly: the nature of the working relationships developed within the smaller team and the exponential growth in their research knowledge and self-confidence. Fourthly: the histories of most of the young people recruited were not predictive as to their 
commitment in training and throughout research activities; they were the equal of many adults the author has co-researched with, and better than some.

\section{COMPLEXITY-INFORMED RESEARCH}

Currently it is difficult to advise funders or commissioners that bids should be considered fluid; that data may be only approximate and that the best evaluation of effectiveness may require waiting ‘until the next generation grows up’ (Heyes, 2007). However, analysis of tensions arising from applying standard evaluation approaches to understanding complex and non-linear phenomena, provides opportunities to consider how to integrate complexity concepts into research into services or programmes designed for human beings.

Bid-writing for grant capture is constrained by deadlines, word and font limitations. Deterministic chaos (Poincaré, 1914) highlights the impossibility of accurately predicting processes or knowledge production and, if integrated, would result in bids characterized by open-endedness and fluidity. Researchers not wishing to foreclose opportunities for emergence could deploy complexity thinking in bids for contracts to evaluate welfare services or programmes. For example, how choice of methods is informed might change, as would consideration of what kind of data to collect and analyse and how much. Sufficient time and space for travelling; nourishment; preparation, post-hoc reflection and support amongst co-researchers to facilitate emergence, would be included always and that what develops or emerges will be different to the sum of the parts, would be acknowledged. Understanding that researchers, research subjects, co-researchers and commissioners are parts of systems is enhanced by the concept of complex adaptive systems. Acknowledging that research may have significant impact, or little or no impact, would free all involved from 
expectations and alter research commissioning. Combined with being open to possibilities of emergence, such an approach would allow data to emerge which is untrammelled by preconceptions and the impact of the 'research environment' (surroundings) on the research would be considered regularly. Because complex adaptive systems cannot be understood by reduction to their parts, the contribution of everyone involved in producing knowledge would be valued. Co-researchers would give informed consent about sharing information with one another and have rights to withdraw from involvement in studies as research subjects do. Considerations of observer (researcher) impact (Burton, 2002), would be included in all research narratives: there would be no 'view from nowhere’ (Nagel, 1986).

Integrating the concept of complex adaptive systems would reinforce understandings of research as a collective endeavour and integrating that of networks and interconnections would remind researchers to be mindful of their impact on all the relationships within the networks. No data would be discounted and commitment to data discussions and feedback with carers, service users and other groups involved would be in-built from a project's start. Agents possess knowledge and capacities to act, adapt and adjust as new information is processed, constantly interacting with their environment. Integrating this concept into research practice would emphasize (should it be necessary) the limitations of researchers' knowledge and information; that researchers can and should learn from and share with all agents involved in research projects, whatever the degree of involvement.

Leading on from the demise of history as the 'master key', researchers' 'pedigree' would be no assurance of success; bidding would become a more open process, with grants being awarded according to strength of content, not according to researchers' curriculum vitae. 
In this section the author has outlined how complexity science concepts could be integrated into conceptualising and undertaking research - ‘complexity-informed research'. Other possibilities for integration can be discerned in analysis of the Northside project. Congruent with the author's own approach to integrating complexity science concepts - not transferring uncritically; not expecting an exact fit or complete explanation, but seeking resonances (see Introduction) - this is not a blueprint, but suggestions for fellow-researchers to develop as they wish. Complexity science cannot address every issue in research projects, nor should researchers apply it so. It emphasizes being mindful of relationships and processes, valuing learnings and understandings as well as knowledge: 'and...and', not 'either ...or'.

Some readers may argue that integration as discussed above is impossible within current structures for commissioning, bidding and research engagement. However, developments such as service users, carers and community groups designing and leading research projects (Green, 2008), demonstrate that established structures and their practices are susceptible to challenge and to change. Making complexity-informed research central to all considerations from bid-writing onwards is difficult, but not impossible.

\section{CONCLUSION}

This paper is not a linear account of research and findings but a narrative of learnings from research processes characterized by: ‘...open-endedness...incompleteness...' (Schwandt, 2007, 224). While learnings discussed here are particular to the author, she anticipates that some or all of this narrative and discussion of complexity-informed research will resonate with researchers at any and every stage in their careers who are seeking ways to develop their research practice and to reflect on and make sense of, research experiences. 
Alvesson and Skoldberg (2009) argue that valid knowledge may be accompanied by unsuccessful action. To adapt this slightly: if reflected upon, unsuccessful or not completely successful action such as the Northside project, may result in valid learnings. The author continues to integrate these and other concepts from complexity science in order to inform and improve her research practice and attention paid to processes, while remaining critically aware that complete understanding of research processes and knowledge production remain as inaccessible to researchers as do planetary movements to astronomers.

\section{REFERENCES}

Alvesson, M. and Skoldberg, K. (2009) Reflexive methodology: New vistas for qualitative research ( $2^{\text {nd }}$ ed.) London: Sage.

Blackman, T. (2001). Complexity theory and the new public management. Social Issues, 1(2): Special Issue on Complexity Science and Social Policy http://www.whb.co.uk/socialissues

Burton, C. (2002). Introduction to complexity. In K. Sweeney \& F. Griffiths (eds.), Complexity and healthcare - An introduction (pp. 1-18). Oxford: Radcliffe Medical Press.

Cilliers, P. (1998). Complexity and postmodernism: Understanding complex systems. London: Routledge. 
Cohen, J. \& Stewart, I. (1994). The collapse of chaos: Discovering simplicity in a complex world. Harmondsworth: Penguin.

Cox, P. (2008). Changing research, research for change: Exploring the perspectives of complexity science. In P. Cox, T. Geisen \& R. Green (eds.), Qualitative research and social change: European contexts (pp. 15-31). Hampshire: Palgrave Macmillan.

Cresswell, J. (2003). Research design: Qualitative, quantitative and mixed model approaches (2nd ed.) Thousand Oaks CA: Sage.

Durand Thomas, M., Blacksmith, J. \& Reno, J. (2000). Utilising insider-outsider research teams in qualitative health research. Qualitative Health Research, 10(6), 819-828. doi: $10.1177 / 104973200129118840$

Ellis, C. (2007) Telling secrets, revealing lives: Relational ethics in research with intimate others. Qualitative Inquiry, 13(1), 3-29. doi: 10.1177/1077800406294947

Green, R. (2008) Bringing about social change: The role of community research. In P. Cox, T. Geisen \& Green, R. (eds.), Qualitative research and social change: European contexts (pp. 75-93). Hampshire: Palgrave Macmillan. 
Gribbin, J. (2004). Deep simplicity: Chaos, complexity and the emergence of life. London: Allen Lane.

Griffiths, F. (2002). Complexity and primary healthcare research. In K. Sweeney \& F. Griffiths (eds.), Complexity and healthcare: An introduction (pp. 149-166). Oxford: Radcliffe Medical Press.

Heyes, J. (2007) Personal communication.

Holland, J. H., Holyoak, K. J., Nisbet, R. E. \& Thagard, P. R. (1986). Induction: Processes of inference, learning and discovery. Cambridge MA: MIT Press.

Jack, G. (2005). Assessing the impact of community programmes working with children and families in disadvantaged areas. Child and Family Social Work, 10(4), 293-304. doi: 10.1111/j.1365-2206.2005.00379.x

Kvale, S. \& Brinkmann, S. (2008). Interviews: Learning the craft of qualitative research interviewing (2nd ed.) Thousand Oaks CA: Sage.

Mainzer, K. (1996). Thinking in complexity (2nd ed.) New York : Springer Verlag. 
Merry, U. (1995). Coping with uncertainty: Insights from the new science of chaos, selforganization and complexity. Westport, CT: Praeger Publishers.

Moore, H. (1994). "Divided we stand": Sex, gender and difference. Feminist Review, 47, 7895. doi: 10.1057/fr.1994.23

Morowitz, H. J. (2002). The emergence of everything: How the world became complex. Oxford: Oxford University Press.

Nagel, T. (1986) The view from nowhere. New York: Oxford University Press

Poincaré, H. (1914). Science and method. London: T. Nelson and Sons.

Robson, C. (2002). Real world research (2nd ed.) Oxford: Blackwell Publishers.

Schwandt, T. A. (2007). Dictionary of qualitative inquiry (3rd ed.) Thousand Oaks CA: Sage.

Stevens, I. \& Cox, P. (2008). Complexity theory: Developing new understandings of child protection in field settings and in residential care. British Journal of Social Work, 38(7), 1320-1336. doi:10.1093/bjsw/bcm052 
Stewart, A. (1998). The ethnographer's method. Thousand Oaks CA: Sage.

The Home Office (1998). Supporting families. London: The Stationery Office.

Trevillion, S. (2000). Social work, social networks and network knowledge. British Journal of Social Work, 30(4), 505-517. doi: 10.1093/bjsw/30.4.505

Varela, F. J. (1989). Reflections on the circulation of concepts between a biology of cognition and systemic family therapy. Family Process, 28, 15-24. doi:10.1111/j.15455300.1989.0095.x

Wolf-Branigin, M. (2009). Applying complexity and emergence in social work education. Social Work Education - The International Journal, 28(2), 115-127. doi:10.1080/02615470802028090

Wolf-Branigin, M. (in press). Measuring complexity: Applications for social work research education. Journal of Teaching for Social Work. 